\title{
AVALIAÇ̃̃O DA INCIDÊNCIA DE ANTRACNOSE, DO DESEMPENHO E ESTADO NUTRICIONAL DE VARIEDADES DE MANGUEIRA, PARA CULTIVO ORGÂNICO, NA REGIÃO CENTRO-NORTE DO ESTADO DE SÃO PAULO ${ }^{1}$
}

\author{
JULIANA ALTAFIN GALLI², LUIS CLÁUDIO PATTERNO SILVEIRA ${ }^{3}$, \\ MARCOS DONIZETI MICHELOTTO ${ }^{2}$, ANTONIO LUCIO MELO MARTINS ${ }^{2}$
}

RESUMO - A mudança do perfil do consumidor, aliada aos riscos da contaminação por agrotóxicos, tem levado à busca de alternativas ecologicamente apropriadas para produção de frutas. Os objetivos deste trabalho foram avaliar a incidência de antracnose, o desempenho e estado nutricional de variedades de mangueira conduzidas organicamente na região de Pindorama-SP. Foram utilizadas 17 variedades de mangueira. O experimento foi instalado em delineamento experimental em blocos completos ao acaso, com 17 tratamentos (variedades) e seis repetições. Foi avaliada a severidade de antracnose nas folhas, através de uma escala diagramática, atribuindo-se notas aos sintomas. Foram avaliados o crescimento e o desenvolvimento (altura da planta, perímetro do tronco e da copa) e o estado nutricional, mediante análise foliar, das diferentes variedades utilizadas. Através dos resultados obtidos, podem-se considerar como muito suscetíveis à antracnose as variedades Bourbon, Rocha e Rosa; e resistentes, as variedades IAC 111, Alfa, Beta e Parvin; as variedades de manga apresentaram o mesmo padrão de crescimento; as maiores alturas da planta corresponderam aos maiores diâmetros do tronco e da copa; a variedade Parvin apresentou o melhor desempenho dentre as variedades estudadas, com relação à resistência à antracnose, altura e diâmetro do caule e da copa, podendo ser recomendada ao cultivo orgânico. As variedades Omega e Alfa também apresentaram bom crescimento, podendo ser indicadas para esse cultivo, pelo menos nessa fase inicial; as variedades Surpresa e Rosa não apresentaram bom desempenho, no campo, em relação às demais, não devendo ser recomendadas para o cultivo orgânico, principalmente a variedade Rosa, bastante suscetível à antracnose. As concentrações de N, P e K foram elevadas na fase vegetativa das plantas, comparadas là baixa concentração de Ca; houve carência de Boro em todas as variedades estudadas. A manga Rosa, provavelmente, sofreu toxicidade ao excesso de manganês, ocasionando diminuição em seu desenvolvimento.

Termos para indexação: Mangifera indica; Colletotrichum gloeosporioides; análise foliar; agricultura orgânica.

\section{EVALUATION OF ANTHRACNOSE INCIDENCE, DEVELOPMENT AND NUTRITIONAL STATUS OF MANGO TREE VARIETIES FOR ORGANIC CULTIVATION IN THE NORTH CENTRAL REGION OF SÃO PAULO STATE}

\begin{abstract}
The consumer's profile change, allied to the risk of toxic substances contamination, is inducing the search for ecological alternatives of fruits production. The objectives of this work were to evaluate the anthracnose incidence, the development and nutritional status of mango varieties organically cultivated in Pindorama, SP. Seventeen mango varieties were used. The experiment was designed in completely randomized blocks, with 17 treatments (varieties) and six replications. The anthracnose severity in leaves was evaluated by a diagrammatic scale, with grades attributed to the symptoms. The growth and development (plant height, stem and crown perimeter) and the nutritional state indicated by leaf analysis were used for evaluation of the varietal behavior. The varieties Bourbon, Rocha and Rosa could be considered very susceptible to anthracnose and IAC 111, Alfa, Beta and Parvin were resistant; the mango varieties presented the same growth pattern; the largest plant heights corresponded to the largest diameters of the stem and crown; the Parvin variety presented the best performance among the varieties in relation to the anthracnose resistance, height and diameter of the stem and crown, and could be recommended for organic cultivation. The Omega and Alfa varieties also presented good development and could be indicated for that cultivation, at least in that initial phase; Surpresa and Rosa varieties did not present good field development in relation to the others, and should not be recommended for the organic cultivation, mainly the variety Rosa, which is quite susceptible to anthracnose. The concentrations of N, P and $\mathrm{K}$ were higher in the vegetative phase of the plants, when compared to the low concentration of $\mathrm{Ca}$; there was lack of Boron in all the studied varieties; Rosa variety probably suffered toxicity to the excess of manganese, causing decrease in its development. Index terms: Mangifera indica; Colletotrichum gloeosporioides; leaf analysis; organic agriculture.
\end{abstract}

'(Trabalho 190/08). Recebido em: 22-07-2008. Aceito para publicação em: 11-02-2009. Trabalho realizado com recursos da FAPESP. ${ }_{2}^{2}$ Pesquisador, Apta Centro Norte, CP 24, CEP 15830-000, Pindorama-SP, E-mail: julianagalli@apta.sp.gov.br, michelotto@apta.sp.gov.br, lmartins@apta.sp.gov.br,

${ }^{3}$ UFLA - Departamento de Entomologia, Cx Postal 3037, CEP: 37200-000, Lavras-MG, E-mail: lcpsilveira@ufla.br 


\section{INTRODUÇÃO}

A manga (Mangifera indica L.) é uma das frutas mais consumidas no mundo. A procura tem aumentado bastante nos mercados interno e externo, alcançando preços compensatórios. O Brasil está entre os nove principais produtores de manga do mundo, com uma área de 67 mil hectares. A comercialização da manga no mercado interno brasileiro centraliza-se em uma única variedade, a norte-americana Tommy Atkins, representando $79 \%$ da área plantada no Brasil (Pinto, 2002).

O binômio saúde/alimentação vem despertando a atenção do consumidor na busca por alimentos mais saudáveis. Não é, portanto, surpreendente que a agricultura orgânica se apresente em ampla expansão em nível mundial, por suas características de sustentabilidade e produtos de qualidade com certificação de origem que atendem à crescente demanda por parte de consumidores mais exigentes. Almeida et al. (2000) afirmam que, nos últimos 50 anos, todos os esforços de pesquisa foram orientados no sentido de desenvolver cultivares de alto rendimento, fortemente dependentes de grandes aportes de insumos e tecnologias, orientadas, principalmente, para a maximização da produtividade, sem maiores preocupações com os aspectos ecológicos. Portanto, é de se esperar que um longo caminho deverá ser percorrido, no sentido de se desenvolver cultivares produtivas, orientadas para alta eficiência no uso de insumos e tecnologias apropriadas à agricultura orgânica.

Segundo Rossetto et al. (1992), o cultivo de manga orgânica no Estado de São Paulo tem a doença antracnose, causada pelo fungo Colletotrichum gloeosporioides Penz., como fator limitante. Essa doença provoca desfolhamento da planta, queda de flores e frutos, e perda da qualidade dos frutos. O fungo ataca ramos novos, folhas, inflorescências e frutos.

Para a mangueira, são poucos os trabalhos que tratam das exigências ou que quantificam a extração de nutrientes pela planta em suas diversas fases de desenvolvimento ou que fornecem as suas proporções nas diversas partes da planta (folhas, frutos, caules e raízes) (Guimarães, 1982). Fernandes \& Nascimento (2004) ressaltam que, na literatura nacional, nada é mencionado sobre a adubação orgânica na mangueira, exceto no plantio. No entanto, este tipo de adubação deve ser estudado na cultura da mangueira, principalmente, aproveitando a disponibilidade regional de adubos orgânicos.

Santos et al. (1973) obtiveram resposta às adubações orgânica e mineral sobre o desenvolvimento inicial da mangueira, variedade Haden, com maiores ganhos em diâmetro do caule e altura das plantas nos tratamentos em que o esterco de gado esteve presente. Goede (1993), trabalhando com doses e fontes de fertilizantes orgânico e mineral, obteve um aumento de produção de 12,25 t/ha para 18,54 t/ha em mangueiras 'Tommy Atkins' com quatro anos de idade.

Apesar dos avanços tecnológicos observados na mangicultura, a fertilização mineral é feita de forma empírica, em virtude da escassez de informações sobre o manejo nutricional adequado para a planta, havendo necessidade de maiores estudos de nutrição e adubação mineral da mangueira (São José, 1986; Fernandes \& Nascimento, 2004). As exigências nutricionais da mangueira foram pouco estudadas (Quaggio, 1986), fato atribuído ao longo ciclo da planta e à informação de que a mangueira não responde à adubação mineral. Estudos demonstram que a adubação adequada, controlada por meio de análises químicas do solo e das folhas, permite ganhos de produção significantes.

Diante do exposto, o presente trabalho teve como objetivos avaliar a incidência de antracnose, o desempenho e estado nutricional de variedades de mangueira conduzidas organicamente na região de Pindorama-SP.

\section{MATERIAL E MÉTODOS}

O trabalho foi conduzido na APTA Polo Centro-Norte, em Pindorama-SP. A região apresenta temperatura média anual de $22,8^{\circ} \mathrm{C}$, precipitação média anual de $1.390,3 \mathrm{~mm}$ e umidade relativa média anual de $71,6 \%$. A área experimental foi limpa e gradeada, e foi feita a análise de solo previamente ao plantio.

Os tratamentos utilizados constituíram-se de 17 variedades de manga: Alfa, Ataulfo, Beta, Bourbon, Bourbon-Vermelha, Espada-Ouro-de-Itaparica, Espada-Stahl, IAC 111, Imperial, Lita, Omega, Palmer, Parvin, Rocha, Rosa, Surpresa e Ubá, enxertadas sobre o porta-enxerto da variedade Manila, também denominada pelo IAC como Carabao.

As correções do solo foram feitas mediante o resultado da análise, com aplicação de 1,5 ton/ha de calcário dolomítico e $600 \mathrm{~kg} /$ ha de hiperfosfato reativo Dejebel ${ }^{\circledR}$ em área total. A adubação na cova consistiu de $10 \mathrm{~kg}$ de esterco de gado curtido e 400 $\mathrm{g}$ de hiperfosfato reativo.

O experimento foi instalado em delineamento experimental em blocos completos ao acaso, com 17 tratamentos (variedades) e seis repetições (blocos), sendo as parcelas compostas de duas plantas. As plantas foram estabelecidas no espaçamento de oito metros entre linhas e quatro e meio metros entre 
plantas na linha. O plantio das mudas foi efetuado em 01-02-2007.

Foi realizada uma adubação de cobertura, com aplicação de $100 \mathrm{~g} / \mathrm{m}$ linear de Yoorin Máster (termofosfato magnesiano - $\mathrm{P}_{2} \mathrm{O}_{5}$ ) entre as plantas na área capinada e $10 \mathrm{~kg}$ de esterco de gado curtido, aplicando-se metade em cada lado da planta, fora da bacia de irrigação.

Para o controle de formigas, foram instaladas barreiras para a proteção física dos troncos das árvores, confeccionadas com material Tetrapak ${ }^{\circledR}$, grampeadas ao redor do porta-enxerto. Foi aplicada nos olheiros dos formigueiros isca granulada natural Macex (composta de extratos naturais de plantas da flora nativa brasileira e polpa de maçã e cítrica, ácidos palmítico, esteárico, oleico, linoleico e cafeína), e, posteriormente foi colocada, junto com a isca, água fervente dentro dos olheiros. O controle das formigas foi intensificado nos meses de janeiro a abril. O controle fitossanitário constituiu-se da pulverização com hidróxido de cobre Supera ${ }^{\circledR}(200 \mathrm{ml} / 100$ litros água), e posteriormente, calda sulfocálcica $\left(100 \mathrm{~g}\right.$ Bordasul ${ }^{\circledR}$ $+500 \mathrm{~g}$ Sulfocal ${ }^{\circledR} / 100$ litros água).

A severidade da antracnose nas folhas foi avaliada mediante uma escala diagramática própria, atribuindo-se notas aos sintomas: 0 - ausência de manchas de antracnose; 1 - até $25 \%$ da área foliar com sintomas; 2 - de 26 - $50 \%$ da área foliar com sintomas; 3 - de 51 - 75\% da área foliar com sintomas; 4 - de 76 - 100\% da área foliar com sintomas de antracnose. As avaliações foram realizadas antes e, após o tratamento fitossanitário, aos 12 meses do plantio. Foi realizada análise de variância, e as médias das notas de duas plantas por repetição foram analisadas estatisticamente, pelo teste de Tukey, a $5 \%$ de probabilidade. Os dados foram transformados em $(\mathrm{x}+1)^{1 / 2}$ para a realização da análise estatística. A classificação da variedade como resistente ou suscetível à antracnose foi relativa à infestação das demais variedades.

Para as avaliações do crescimento das copas, foram realizadas medições mensais: a altura da planta foi medida com uma régua graduada, e o valor, expresso em $\mathrm{cm}$. $\mathrm{O}$ diâmetro do tronco foi medido com paquímetro digital, a $15 \mathrm{~cm}$ do solo, e o valor, expresso em mm. Foram tomados dois diâmetros transversais da copa: um no sentido da linha de plantio e o outro no sentido da entrelinha, utilizando-se da média. A amostra das folhas para as determinações dos nutrientes $\mathrm{N}, \mathrm{P}, \mathrm{K}, \mathrm{Ca}, \mathrm{Mg}, \mathrm{S}, \mathrm{Cu}, \mathrm{Fe}, \mathrm{Mn}$ e $\mathrm{Zn}$ foi composta de 40 folhas para cada variedade. Foram recolhidas folhas a uma altura mediana da copa, na parte mediana do ramo com quatro meses de idade.

Foi realizada análise de variância dos dados da última avaliação, para altura da copa e diâmetro do tronco e da copa, em blocos casualizados, e as médias, analisadas estatisticamente, pelo teste de Tukey, a 5\% de probabilidade.

\section{RESULTADOS E DISCUSSÃO}

Os resultados da média de notas de sintomas de antracnose das variedades de manga estão expressos na Tabela 1. Verifica-se, estatisticamente, antes das pulverizações, que a variedade Bourbon foi a mais afetada pela antracnose, com notas variando de 1 a 4 . As variedades Rocha e Rosa também se mostraram suscetíveis, com notas variando de 0 a 3 e 0 a 4 , respectivamente, sem diferir estatisticamente da variedade Bourbon. Os resultados estão de acordo com Ribeiro (1997), que relata que a variedade Bourbon é extremamente suscetível à antracnose, nas condições do Estado de São Paulo.

Zambolim \& Junqueira (2004) consideram as variedades Haden, Bourbon e Palmer como bastante suscetíveis à antracnose. No presente experimento, a variedade Palmer apresentou notas variando de 0 a 1 , ficando em posição intermediária entre as variedades muito suscetíveis e as resistentes.

A variedade Parvin foi a única que apresentou a totalidade das plantas sem sintomas de antracnose, podendo ser considerada como resistente. De origem americana, descendente de uma semente de 'Haden' plantada na residência de Clint Parvin, Bradenton, Florida, essa variedade possui frutos de polpa firme, sem fibras e de ótimo aroma e sabor, podendo ser uma ótima opção para o cultivo orgânico. As variedades IAC 111, Alfa e Beta também apresentaram elevado grau de resistência ao patógeno. Segundo Lorenzi et al. (2006), a variedade Alfa, resultante do cruzamento de "Mallika" com "Van Dyke", é a mais resistente à antracnose.

$\mathrm{Na}$ avaliação realizada após as pulverizações, verificou-se que os produtos utilizados foram eficientes no controle da doença, diminuindo consideravelmente a incidência de sintomas nas plantas, principalmente na variedade Bourbon, que foi a mais suscetível do ensaio. A variedade Rocha apresentou poucos sintomas comparado com a primeira avaliação, sendo uma das que mais responderam positivamente à ação dos produtos.

Através dos resultados referentes à altura das variedades de manga, mensalmente avaliadas, verificou-se que as variedades que de início apresentaram maiores alturas, por ocasião do plantio, nem sempre mantiveram essa condição, como é o caso das variedades Surpresa e Rosa. A variedade Surpresa não apresentou crescimento visível durante os meses 
de maio a fevereiro, e a variedade Rosa foi a que obteve o pior desempenho do experimento, com a morte dos ramos principais a partir do segundo mês do plantio.

Na última avaliação, em abril de 2008 (Tabela 2), verificou-se que, na média, as maiores alturas foram alcançadas pelas variedades Parvin (153,7 $\mathrm{cm})$ e Lita $(152,8 \mathrm{~cm})$, sem diferir significativamente das demais variedades, com exceção de Surpresa e Rosa. As variedades Espada-Ouro-de-Itaparica, IAC 111, Ubá, Espada-Stahl e Ataulfo constituíram o grupo das variedades intermediárias. Todas as variedades apresentaram o mesmo padrão de crescimento, com crescimento lento durante os meses de abril a dezembro e rápido crescimento nos meses de janeiro e fevereiro. A variedade Omega foi a que mais se desenvolveu durante o período avaliado, com crescimento de $138 \%$ do plantio até a última avaliação, seguida da variedade Alfa e Ataulfo.

O fraco desempenho da variedade Rosa pode ser explicado, em parte, pela alta suscetibilidade dessa variedade à antracnose, como mostrado na Tabela 1. Porém, a variedade Bourbon, que apresentou a maior infecção por antracnose do experimento, teve um crescimento constante durante o período avaliado, totalizando $63,39 \%$, contra o crescimento de $8,42 \%$ da variedade Rosa. Portanto, há outros fatores envolvidos no baixo desempenho dessa variedade.

Segundo Simão (1998), os conhecimentos sobre o hábito de crescimento da mangueira fornecem meios para correlacionar sua forma e suas dimensões, com um espaçamento compatível com sua atividade biológica, evitando erros na formação do pomar, os quais se refletirão na produtividade.

A variedade Lita apresentou o maior diâmetro de tronco, desde o início do plantio. Na última avaliação (Tabela 2), verificou-se que as variedades não diferiram estatisticamente da variedade Lita, com exceção das variedades Surpresa e Rosa, que, assim como no quesito altura, foram as que apresentaram menor crescimento do experimento.

Em geral, as maiores alturas de plantas corresponderam aos maiores diâmetros de tronco. Os diâmetros apresentaram crescimento gradual e lento nos primeiros meses de plantio e rápido crescimento a partir de setembro de 2007 . A variedade Omega foi a que mais se desenvolveu no período, com crescimento de $285,57 \%$, seguida de Ataulfo $(211,25 \%)$ e Alfa $(207,91 \%)$. As variedades Surpresa e Rosa, assim como para altura, apresentaram baixo crescimento de diâmetro de tronco.

A variedade Parvin apresentou o maior diâmetro de copa, diferindo estatisticamente apenas da variedade Rosa. A variedade Rosa apresentou o menor diâmetro de copa do experimento. Houve correlação positiva $(r=0,857126)$ entre altura da planta e diâmetro de copa das 17 variedades, permitindo-se, de modo geral, afirmar que as variedades com maior altura apresentaram maior diâmetro de copa. Soares (1994) avaliou o desenvolvimento vegetativo de 19 variedades de manga, aos quatro anos de idade, e também verificou correlação positiva entre as variáveis altura da planta e diâmetro da copa.

Os valores do conteúdo de nutrientes nas folhas das variedades de mangueira encontram-se na Tabela 3. Os teores de macronutrientes nas folhas das plantas na fase vegetativa obedeceram, de modo geral, à seguinte ordem: $\mathrm{N}>\mathrm{Ca}>\mathrm{K}>\mathrm{P}>\mathrm{S}>\mathrm{Mg}$. Os resultados discordam dos encontrados por Medeiros et al. (2003), que verificaram, em mangueiras da variedade Tommy Atkins na fase vegetativa, teores de macronutrientes nas folhas da ordem de $\mathrm{Ca}>\mathrm{N}>\mathrm{K}>\mathrm{Mg}>\mathrm{P}$, que foram semelhantes nas quatro fases fenológicas (vegetativa, pré-floração, floração e maturação dos frutos).

Segundo Quaggio et al. (1997), as faixas de teores adequados de nutrientes em folhas de mangueira, são, para macronutrientes $(\mathrm{g} / \mathrm{kg})$ : N (1314), P (0,8-0,6), K (5-10), Ca (20-35), Mg (2,5-5,0) e $\mathrm{S}(0,8-1,8)$; e para micronutrientes $(\mathrm{mg} / \mathrm{kg})$ : B (50-100), Cu (10-50), Fe (50-200), Mn (50-100) e Zn (20-40).

O teor de nitrogênio das folhas mostrou-se excessivo para todas as variedades estudadas, variando de $18,2 \mathrm{~g} / \mathrm{kg}$, nas variedades Ataulfo, Beta, IAC 111, a $22,4 \mathrm{~g} / \mathrm{kg}$, na variedade Bourbon-Vermelha. A maior concentração de $\mathrm{N}$ do presente experimento deu-se pelas plantas estarem na fase vegetativa. A concentração de $\mathrm{N}$ é alta no período vegetativo e decresce nas fases seguintes. Esse elemento é influente no crescimento vegetativo e no número de gemas florais produtivas da mangueira (Albuquerque et al., 1999). Resultados semelhantes foram obtidos por Silva \& Lima (2001), que, com o objetivo de avaliar o efeito da aplicação de húmus de minhoca e de esterco de gado na concentração foliar de nutrientes e na produção de mangas "Tommy Atkins", verificaram teores de $\mathrm{N}$ bastante elevados, variando de 17,63 a $22,25 \mathrm{~g} / \mathrm{kg}$.

$\mathrm{O}$ excesso de nitrogênio acarreta problemas na cultura. Young (1960) observou aumento na incidência de "soft nose" com o aumento da adubação nitrogenada em baixos níveis de Ca. Em outro experimento, Young \& Miner (1961) observaram que, com o aumento nos teores de N, a incidência de "soft nose" aumentou de 7\% (testemunha com baixo N) para 78\%. Pinto (2000) relata que, no Brasil, pomares de mangueira com teor de $\mathrm{N}$ foliar $>12 \mathrm{~g} / \mathrm{kg}$ tendem a ter maior incidência de frutos com coloração da 
casca verde.

Quanto aos teores de fósforo, as variedades Ataulfo, Bourbon, Palmer, Rosa, Surpresa e Ubá apresentaram valores adequados do nutriente. As demais variedades apresentaram excesso de $\mathrm{P}$, chegando a 3,1 g/kg na variedade Rocha. Os altos índices do elemento nas folhas são resultado das adubações com hiperfosfato reativo e Yoriin Máster, produtos com boa concentração do nutriente.

A concentração de potássio nas folhas de mangueira apresentou altos teores, variando de 9 a 15,3 g/ kg. As variedades Lita, Omega, Parvin, Rocha e Surpresa apresentaram teores adequados do elemento, e as demais variedades apresentaram excesso. De modo geral, pode-se dizer que as elevadas concentrações de NPK encontradas no experimento são ocasionadas pelo estado fenológico das plantas, que se encontram na fase vegetativa, concordando com os relatos de outros pesquisadores (Fernandes \& Nascimento, 2004; Albuquerque et al., 1999; Avilan, 1971).

Com relação ao cálcio, todas as concentrações encontradas estavam abaixo da recomendada, com exceção das variedades IAC $111(20,6 \mathrm{~g} / \mathrm{kg})$ e Lita $(20,2 \mathrm{~g} / \mathrm{kg})$. Silva \& Lima (2001) também encontraram índices desse elemento menores que os adequados, e uma relação N/Ca nas folhas maior que 1,5 .

Devido à baixa mobilidade do cálcio na planta, há necessidade de fornecimento constante desse nutriente. Para tanto, a forma mais interessante de fornecer cálcio seria aplicá-lo ao solo de modo que a solução do solo possa suprir o elemento constantemente aos frutos (Prado, 2004). No presente experimento, foram aplicados calcário, hiperfosfato reativo e calda sulfocálcica, produtos com bom suprimento de cálcio. A baixa concentração do nutriente nas folhas ocorreu devido à fase vegetativa das plantas. O Ca sofre aumento na concentração, na fase de formação dos frutos (Avilan, 1971).

Vários autores citam na literatura a relação entre a baixa concentração de cálcio e a desordem fisiológica em frutos de mangueira (Van Eeden, 1992; Pinto et al., 2002). Entre os macronutrientes, o cálcio coloca-se como mais limitante para a produção da mangueira (Pinto et al., 2002).

Os teores de magnésio ficaram abaixo do adequado para todas as variedades, com exceção da Palmer (2,7g/kg). Medeiros et al. (2003) verificaram carência nutricional de $\mathrm{Mg}$ na análise foliar de mangas Tommy Atkins, nos três plantios estudados. $\mathrm{O}$ magnésio, além de fazer parte da clorofila, é ativador de numerosas enzimas. É elemento essencial para a absorção de $\mathrm{P}$, e sua absorção é inibida em presença de altas concentrações de $\mathrm{K}$, podendo causar deficiência
(Rodriguez et al., 1986). No presente experimento, houve excesso de potássio, podendo ser uma das causas da deficiência de $\mathrm{Mg}$ nas folhas.

$\mathrm{O}$ enxofre apresentou concentrações adequadas para a maioria das variedades, entre $0,8 \mathrm{e}$ $1,8 \mathrm{~kg} / \mathrm{ha}$, de acordo com Quaggio et al. (1997), e concentrações em excesso para as variedades Alfa (2,1 kg/ha), Ataulfo (1,9 kg/ha), Omega (1,9 kg/ha), Palmer (1,9 kg/ha), Rocha (2,0 kg/ha) e Ubá $(2,1 \mathrm{~kg} /$ ha) (Tabela 3 ).

O micronutriente Boro foi encontrado em concentrações abaixo da recomendada para todas as variedades estudadas, com teores entre 11 e $26 \mathrm{mg} /$ $\mathrm{kg}$. À medida que aumenta o conhecimento disponível sobre as necessidades minerais das frutíferas, mais se constata a grande importância do boro na nutrição dessas espécies. Uma característica geral da deficiência de boro em frutíferas relaciona-se com a floração e o pegamento de frutos. Geralmente, a floração é excessiva, porém com baixo pegamento dos frutos, que caem prematuramente, o que provavelmente está relacionado com a importância do boro na germinação do grão de pólen e crescimento do tubo polínico (Quaggio \& Piza Jr, 2001). Em manga, a deficiência de boro ocasiona panículas florais com tamanho reduzido e menor número de flores hermafroditas (ideais) e, portanto, retém menos frutos do que os de plantas bem supridas de boro (Singh \& Dhillon, 1987).

Os teores de cobre mostraram-se adequados para todas as variedades, entre 11 e $19 \mathrm{mg} / \mathrm{kg}$, respectivamente, para as variedades Lita e Espada-Stahl, em consequência das pulverizações efetuadas com produtos à base de cobre. As concentrações de ferro variaram de 55 a $191 \mathrm{mg} / \mathrm{kg}$, respectivamente, para as variedades Espada-Ouro-de-Itaparica e Rosa, apresentando quantidades dentro da faixa recomendada para todas as variedades. Segundo Quaggio \& Pizza Jr. (2001), no Brasil, à exceção de alguns solos do Nordeste, nas demais regiões, a deficiência de ferro pode ser considerada improvável, podendo ocorrer quando induzida por excesso de manganês, quando há drenagem insuficiente do solo.

Todas as variedades apresentaram excessiva concentração do nutriente manganês, com destaque para a variedade Rosa (1940 mg/kg), quando o máximo recomendado é de $100 \mathrm{mg} / \mathrm{kg}$. Silva \& Lima (2001) também encontraram teores de manganês maiores que os recomendados para folhas de mangueira da variedade Tommy Atkins entre $419 \mathrm{e}$ $705 \mathrm{mg} / \mathrm{kg}$. O manganês é um dos micronutrientes requeridos para o crescimento normal das plantas. Ele apresenta efeitos marcantes na nutrição das plantas, tanto do ponto de vista de deficiência como 
de toxicidade. Ambos os efeitos causam perdas significativas na produção das plantas cultivadas (Borkert et al., 2001). Em solos ácidos, é mais provável que a toxicidade de manganês limite o crescimento das plantas.

O íon $\mathrm{Mn}^{2+}$ é a espécie química absorvida pelas raízes das plantas. A absorção é considerada um processo químico controlado pela atividade de $\mathrm{Mn}^{2+}$ na solução do solo. Dessa forma, a composição química do solo e da rizosfera exerce grande influência na absorção de manganês. Devido a esse fato, existem grandes diferenças entre as plantas na absorção de manganês (Silva, 1976; Foy et al., 1988). Esses resultados estão de acordo com os do experimento, que permitem verificar as diferenças entre as variedades de manga quanto à absorção dos nutrientes. A variedade Rosa, que apresentou o maior teor de $\mathrm{Mn}$ do experimento, foi a que teve menor crescimento, em todos os parâmetros avaliados (altura, diâmetro do tronco e diâmetro da copa), podendo ser explicado pela maior absorção e, consequentemente, maior toxicidade ao micronutriente manganês.

Quaggio \& Piza Jr.(2001) relatam que os teores foliares de manganês revelados pela análise de tecidos de manga são excepcionalmente altos, apontando para um consumo de luxo desse nutriente.
Apesar do alto teor de manganês em todas as variedades, os teores de ferro apresentaram-se em níveis adequados, contrariando os resultados de Lee (1972), que relatou a ocorrência de deficiência de ferro induzida pela alta concentração de manganês no solo.

As variedades Ataulfo, Bourbon, Imperial, Palmer e Surpresa apresentaram concentrações de zinco inferiores à recomendada. As demais variedades apresentaram níveis adequados do micronutriente. Segundo Pereira et al. (2005), o boro e o zinco são os micronutrientes mais importantes para a mangueira.

É importante o conhecimento dos períodos de maiores exigências das plantas, pois assim pode-se programar a adubação para que esses nutrientes estejam disponíveis na época em que são exigidos pela planta. Quando ocorrer a translocação dos nutrientes para os frutos, deve-se evitar que os teores caiam a níveis tão baixos que proporcionem, no ano seguinte, baixa produção, levando a planta a ter de se recuperar antes de voltar à produção normal. A este comportamento da planta denomina-se alternância de produção e, segundo diversos autores, este fenômeno, além de estar ligado a fatores de ordem nutricional, pode ser causado também por fatores de ordem genética e de meio ambiente (Avilan, 1971).

TABELA 1- Média de notas relativas aos sintomas de infecção por antracnose em variedades de manga cultivadas em sistema orgânico, antes e após pulverizações.

\begin{tabular}{lcccccc}
\hline Variedades & \multicolumn{3}{c}{ Notas antes pulverizações } & \multicolumn{3}{c}{ Notas após pulverizações } \\
\hline Bourbon & 2,500 & $\mathrm{a}^{1}$ & $(1-4)$ & 1,500 & $\mathrm{a}$ & $(0-3)$ \\
Rocha & 1,833 & $\mathrm{ab}$ & $(0-3)$ & 0,500 & $\mathrm{ab}$ & $(0-1)$ \\
Rosa & 1,833 & $\mathrm{ab}$ & $(0-4)$ & 1,083 & $\mathrm{ab}$ & $(0-3)$ \\
Ataulfo & 1,083 & $\mathrm{bc}$ & $(0-2)$ & 0,833 & $\mathrm{ab}$ & $(0-3)$ \\
Ubá & 1,000 & $\mathrm{bcd}$ & $(0-3)$ & 0,917 & $\mathrm{ab}$ & $(0-4)$ \\
Palmer & 0,667 & $\mathrm{cde}$ & $(0-3)$ & 0,667 & $\mathrm{ab}$ & $(0-2)$ \\
Espada-Stahl & 0,583 & $\mathrm{cde}$ & $(0-1)$ & 0,333 & $\mathrm{ab}$ & $(0-1)$ \\
Boubon-Vermelha & 0,455 & $\mathrm{cde}$ & $(0-2)$ & 0,583 & $\mathrm{ab}$ & $(0-2)$ \\
Surpresa & 0,417 & $\mathrm{cde}$ & $(0-1)$ & 0,750 & $\mathrm{ab}$ & $(0-2)$ \\
Imperial & 0,333 & $\mathrm{cde}$ & $(0-1)$ & 0,583 & $\mathrm{ab}$ & $(0-2)$ \\
Lita & 0,333 & $\mathrm{cde}$ & $(0-1)$ & 0,500 & $\mathrm{ab}$ & $(0-2)$ \\
Espada-Ouro & 0,250 & $\mathrm{cde}$ & $(0-1)$ & 0,500 & $\mathrm{ab}$ & $(0-2)$ \\
Omega & 0,273 & $\mathrm{cde}$ & $(0-1)$ & 0,833 & $\mathrm{ab}$ & $(0-4)$ \\
IAC 111 & 0,083 & de & $(0-1)$ & 0,667 & $\mathrm{ab}$ & $(0-1)$ \\
Alfa & 0,083 & de & $(0-1)$ & 0,167 & $\mathrm{~b}$ & $(0-1)$ \\
Beta & 0,091 & de & $(0-1)$ & 0,500 & $\mathrm{ab}$ & $(0-2)$ \\
Parvin & 0,000 & $\mathrm{e}$ & $(0)$ & 0,167 & $\mathrm{~b}$ & $(0-1)$ \\
\hline F & $11,49 * *$ & & & $1,85^{*}$ & \\
CV & 14,12 & & & 17,74 & \\
\hline
\end{tabular}

${ }^{1}$ Médias seguidas pela mesma letra não diferem entre si, pelo teste de Tukey, a 5\% de probabilidade; "Significativo, a 5\% de probabilidade; ${ }^{* *}$ Significativo, a $1 \%$ de probabilidade. 
TABELA 2 - Altura de plantas, diâmetro de tronco e diâmetro de copa de dezessete variedades de manga, aos 14 meses do plantio.

\begin{tabular}{|c|c|c|c|}
\hline Variedades & Altura plantas $(\mathrm{cm})$ & Diâmetro tronco $(\mathrm{mm})$ & Diâmetro copa $(\mathrm{cm})$ \\
\hline Parvin & 153,7 a & 31,51 a & 106,2 a \\
\hline Lita & 152,8 a & 33,81 a & $99,0 \quad \mathrm{a}$ \\
\hline Ataulfo & $141,8 \mathrm{ab}$ & $28,12 \mathrm{ab}$ & 94,0 a \\
\hline Esp.-Stahl & $140,7 \mathrm{ab}$ & $28,94 \mathrm{ab}$ & $82,7 \mathrm{ab}$ \\
\hline IAC 111 & $138,1 \mathrm{ab}$ & $25,45 a b c$ & 88,7 a \\
\hline Ubá & $136,7 \mathrm{ab}$ & $24,78 \mathrm{abc}$ & 87,5 a \\
\hline Esp.-Ouro & $132,2 \mathrm{ab}$ & $24,61 \mathrm{abc}$ & 87,2 a \\
\hline Beta & $126,0 \mathrm{abc}$ & $27,42 \mathrm{ab}$ & $68,12 \mathrm{ab}$ \\
\hline Alfa & $125,7 \mathrm{abc}$ & $26,85 \mathrm{ab}$ & 92,3 a \\
\hline Palmer & $122,0 \mathrm{abc}$ & $23,75 \mathrm{abc}$ & $83,7 \mathrm{ab}$ \\
\hline Omega & $118,9 \mathrm{abc}$ & $25,91 \mathrm{ab}$ & $79,5 \mathrm{ab}$ \\
\hline B.-Vermelha & $117,2 \mathrm{abc}$ & $27,98 \mathrm{ab}$ & $72,3 \mathrm{ab}$ \\
\hline Imperial & $116,9 \mathrm{abc}$ & $28,67 \mathrm{ab}$ & 88,1 a \\
\hline Bourbon & $114,7 \mathrm{abc}$ & $25,32 \mathrm{abc}$ & 84,6 ab \\
\hline Rocha & 113,9 abc & 22,96 abc & $56,2 \mathrm{ab}$ \\
\hline Surpresa & 107,2 bc & $18,28 \quad b c$ & $52,7 \mathrm{ab}$ \\
\hline Rosa & $87,6 \quad \mathrm{c}$ & $14,51 \quad \mathrm{c}$ & $27,5 \quad b$ \\
\hline $\mathrm{F}$ & $4,22^{* *}$ & 4,24 ** & $2,78^{* *}$ \\
\hline CV $(\%)$ & 15,97 & 20,85 & 35,62 \\
\hline
\end{tabular}

Médias seguidas pela mesma letra não diferem entre si, pelo teste de Tukey, a 5\% de probabilidade; "' Significativo, a 1\% de probabilidade.

TABELA 3 - Análise foliar de macro e micronutrientes de dezessete variedades de mangueira.

\begin{tabular}{cccccccccccc}
\hline Variedades & $\mathrm{N}$ & $\mathrm{P}$ & $\mathrm{K}$ & $\mathrm{C} / \mathrm{Ca}$ & $\mathrm{Mg}$ & $\mathrm{S}$ & $\mathrm{B}$ & $\mathrm{Cu}$ & $\mathrm{Fe}$ & $\mathrm{Mn}$ & $\mathrm{Zn}$ \\
\hline Alfa & 18,9 & 1,8 & 12,3 & 17,2 & 1,4 & 2,1 & 24 & 16 & 132 & 710 & 20 \\
Ataulfo & 18,2 & 1,5 & 11,2 & 15,5 & 1,3 & 1,9 & 18 & 14 & 136 & 830 & 17 \\
Beta & 18,2 & 2,2 & 10,4 & 17,3 & 1,2 & 1,8 & 14 & 13 & 92 & 730 & 26 \\
Bourbon & 18,6 & 1,5 & 11,7 & 15,0 & 1,0 & 1,8 & 14 & 14 & 172 & 930 & 18 \\
B.-Vermelha & 22,4 & 2,0 & 11,5 & 13,0 & 1,4 & 1,7 & 13 & 17 & 73 & 430 & 20 \\
Esp.-Ouro & 20,0 & 1,9 & 11,7 & 13,7 & 1,0 & 1,5 & 11 & 14 & 55 & 640 & 20 \\
Esp.-Stahl & 18,9 & 2,9 & 10,5 & 17,5 & 1,5 & 1,7 & 25 & 19 & 73 & 610 & 22 \\
IAC 111 & 18,2 & 1,9 & 11,3 & 20,6 & 1,9 & 1,7 & 15 & 15 & 101 & 560 & 34 \\
Imperial & 20,7 & 2,7 & 10,4 & 19,0 & 2,0 & 1,6 & 19 & 13 & 139 & 1020 & 16 \\
Lita & 20,0 & 2,4 & 9,6 & 20,2 & 1,6 & 1,6 & 18 & 11 & 94 & 830 & 23 \\
Ômega & 19,3 & 2,9 & 9,6 & 17,0 & 2,4 & 1,9 & 17 & 14 & 170 & 570 & 26 \\
Palmer & 21,0 & 1,6 & 15,3 & 16,5 & 2,7 & 1,9 & 19 & 13 & 60 & 450 & 17 \\
Parvin & 20,7 & 2,3 & 9,4 & 19,1 & 1,9 & 1,7 & 13 & 14 & 107 & 690 & 25 \\
Rocha & 18,9 & 3,1 & 9,0 & 18,4 & 1,7 & 2,0 & 14 & 16 & 164 & 950 & 20 \\
Rosa & 21,4 & 1,4 & 12,2 & 19,5 & 1,6 & 1,6 & 26 & 17 & 191 & 1940 & 20 \\
Surpresa & 20,7 & 1,5 & 9,0 & 16,0 & 1,7 & 1,6 & 25 & 14 & 105 & 460 & 18 \\
Ubá & 20,7 & 1,6 & 13,4 & 12,9 & 1,6 & 2,1 & 12 & 15 & 108 & 340 & 20 \\
\hline
\end{tabular}




\section{CONCLUSÕES}

1 - Das variedades estudadas na fase vegetativa, podem-se considerar como muito suscetíveis à antracnose as variedades Bourbon, Rocha e Rosa; e resistentes, as variedades IAC 111, Alfa, Beta e Parvin.

2 - A variedade Parvin apresentou o melhor desempenho dentre as variedades estudadas, com relação à resistência à antracnose, altura e diâmetro do caule e da copa, podendo ser recomendada ao cultivo orgânico.

3 - As variedades Surpresa e Rosa não apresentaram bom desempenho no campo em relação às demais, na fase vegetativa, principalmente a variedade Rosa, bastante suscetível à antracnose.

4 - As concentrações de N, P e K são elevadas na fase vegetativa das plantas, comparadas com a baixa concentração de Ca. Houve carência de Boro em todas as variedades estudadas. A manga Rosa sofreu toxicidade ao excesso de manganês, ocasionando diminuição em seu crescimento.

\section{AGRADECIMENTOS}

À COAGROSOL - Cooperativa de Agricultores Solidários de Itápolis, pela orientação na condução orgânica do experimento. À FAPESP, pelo auxílio financeiro a este projeto.

\section{REFERÊNCIAS}

ALBUQUERQUE, J.A.S. de; MOUCO, M.A. do C.; MEDINA, V.D.; SANTOS, C.R. dos; TAVARES, S.C.C. de H. O cultivo da mangueira irrigada no semiárido brasileiro. Petrolina: Embrapa Semiárido/ VALEXPORT, 1999. 77p.

ALMEIDA, D.L.; AZEVEDO, M.S.F.R.; CARDOSO, M.O .; DE-POLLI, H.; GUERRA, J.G.M.; MEDEIROS, C.A.B.; NEVES, M.C.P.; NUNES, M.U.C.; RODRIGUES, H.R.; SAMINEZ, T.C.O; VIEIRA, R.C.M. Agricultura Orgânica: instrumento para a sustentabilidade dos sistemas de produção e valoração de produtos agropecuários. Seropédica: Embrapa Agrobiologia, 2000. 22p. (Documentos, 122).

AVILAN, R.L. Variaciones de los níveles de nitrogen, fosforo, potassio y calcio en las hojas de mango (Mangifera indica L.) atraves de un ciclo de produción. Agronomia Tropical, Maracay, v.21, n.1, p.3-10, 1971.

BORKERT, C.M.; PAVAN, M.A.; BATAGLIA, O.C. Disponibilidade e avaliação de elementos catiônicos: ferro e manganês. In: FERREIRA, M.E.; CRUZ,
M.C.P. da; RAIJ, B. van; ABREU, C.A. de. Micronutrientes e elementos tóxicos na agricultura. Jaboticabal: CNPq/Fapesp/Potafós, 2001. p.151-185.

FERNANDES, F.M.; NASCIMENTO, V.M. do. Fertilidade do solo e nutrição da mangueira. In: ROZANE, D.E.; DAREZZO, R.J.; AGUIAR, R.L.; AGUILERA, G.H.A.; ZAMBOLIM, L. Manga: produção integrada, industrialização e comercialização. Viçosa: UFV, 2004. p.179-198.

FOY, C.D.; SCOTT, B.J.; FISHER, J.A. Genetic differences in plant tolerance to manganese toxicity. In: GRAHAM, R.D.; HANNAM, R.J.; UREN, N.C. (Ed.). Manganese in soils and plants. Dordrecht: Kluwer Academic Publishers, 1988. p.293-307.

GOEDE, P.B. 'n Vergelyling tussen verrykte organiese bemesting en anorganiese bemesting, en verskillende toedieningstye op mango's t.o.v. produksie, kwaliteit en ekonomie. South African Mango Growers' Association Yearbook, Lonsdale, v.13, p.76-78, 1993.

GUIMARÃES, P.T.G. Nutrição e adubação da mangueira. Informe Agropecuário, Belo Horizonte, v.8, p.28-35, 1982

LEE, C. R. Interrelationships o aluminum and manganese on the potato plant. Agronomy Journal, Madison, v. 64, p.546-549, 1972.

LORENZI, H.; BACHER, L.; LACERDA, M.; SARTORI, S. Frutas brasileiras e exóticas cultivadas. São Paulo: Instituto Plantarum de Estudos da Flora, 2006. 640 p.

MEDEIROS, A.A. de; AMORIM, J.R.A. de; SILVA, D.J.; GUEDES, F.X.; GUERRA, A.G.; DANTAS, J.A. Composição mineral de folhas e exportação de nutrientes pelos frutos de mangueira, em cultivo irrigado, no Rio Grande do Norte. Natal: EMPARN, 2003. 13p. (Comunicado Técnico, 30)

PEREIRA, M.E.C. (Org.); FONSECA, N. (Org.); SOUZA, F. V. D. (Org.). Manga: o produtor pergunta, a Embrapa responde. Brasília: Embrapa Informação Tecnológica, 2005. 184p.

PINTO, A.C. de Q. A produção, o consumo e a qualidade da manga no Brasil. Revista Brasileira de Fruticultura, Jaboticabal, v.24, n.3, p.597, 2002.

PINTO, A.C. de Q. Teorática no cultivo da manga: sinopse. Planaltina: Embrapa Cerrados, 2000.39p.

PINTO, P. A. C.; DIAS, L. E.; CHOUDHURY, M. M.; VIEIRA, G. Evaluation of the nutritional status of mango Tommy Atkins in the Sub Middle São Francisco river valley: establishment of norms DRIS. In: INTERNATIONAL MANGO SYMPOSIUM, 7. 
2002, Recife. Abstracts ... v.1.

PRADO, R. de M. Nutrição e desordens fisiológicas na cultura da manga. In: ROZANE, D.E.; DAREZZO, R.J.; AGUIAR, R.L.; AGUILERA, G.H.A.; ZAMBOLIM, L. Manga: Produção integrada, industrialização e comercialização. Viçosa: UFV, 2004. p.199-232.

QUAGGIO, J.A. Adubação e calagem para a mangueira e qualidade dos frutos. In: SÃO JOSÉ, A.R.; SOUZA, I.V.B.; MARTINS FILHO, J.; MORAIS, O.M. (Coord.). Manga: tecnologia de produção e mercado. Vitória da Conquista: DFZ/UESB, 1986. p.106-35.

QUAGGIO, J. A.; PIZA JUNIOR, C. T. Micronutrientes para frutíferas tropicais. In: FERREIRA, M. E.; CRUZ, M. C. P.; RAIJ, B. van; ABREU, C. A. (Ed.). Micronutrientes tóxicos e metais pesados na agricultura. Jaboticabal: $\mathrm{CNPq} /$ Fapesp/Potafós, 2001. p. 459-491.

QUAGGIO, J.A.; RAIJ, B. van; PIZA JR., C.T. Frutíferas. In: RAIJ, B. van; CANTARELLA, H.; QUAGGIO, J.A.; FURLANI, A.M.C. Recomendações de adubação e calagem para o Estado de São Paulo. 2.ed. Campinas: Instituto Agronômico, 1997. p.121-130. (Boletim Técnico, 100)

RIBEIRO, I.J.A. Doenças da mangueira (Mangifera indica L.). In: KIMATI, H.; AMORIM, A.; BERGAMIN FILHO, L.E.A.; REZENDE, J.A.M. (Ed.) Manual de fitopatologia: doenças das plantas cultivadas. 3.ed. São Paulo: Agronômica Ceres, 1997. v.2, p.511-524.

RODRIGUEZ, A.P.M.; GUILHERME, M.R.; KLIEMANN, H.J.; GENÚ, P.J. de C.; QUEIROZ, E.F. de. Nutrição mineral e adubação da mangueira (Mangifera indica L.). In: HAAG, H.P. (Coord.). Nutrição mineral e adubação de frutíferas tropicais no Brasil. Campinas: Fundação Cargill, 1986. p.205-245.

ROSSETTO, J.C.; GODOY, I. J.; GALLO, P. B.; SABINO, J.C.; MARTINS, A. L. M.; SOARES, N.B.; BORTOLETTO, N.; PAULO, E.M.; KUBO, R. Recommendations for organic production of mango in the state of São Paulo, Brazil. In: INTERNATIONAL SCIENTIFIC CONFERENCE, 9, 1992, São Paulo. Proceedings... Zentrum: U. köpke \& D.G. Schulz, 1992. v.1, p.133-138.

SANTOS, R.R. dos; VEIGA, A. DE A.; SOARES, E.; TEÓFILO SOBRINHO, J.; IGUE, T. Efeitos de NPK e matéria orgânica no desenvolvimento inicial da mangueira (Mangifera indica L.) In: CONGRESSO BRASILEIRO DE FRUTICULTURA, 2., 1973, Viçosa. Anais... Viçosa: Sociedade Brasileira de
Fruticultura, 1973. v.2, p.399-410.

SÃO JOSÉ, A.R. Considerações gerais sobre a mangicultura. In: SÃO JOSÉ, A.R.; SOUZA, I.V.B.; MARTINS FILHO, J.; MORAIS, O.M. (Coord.). Manga: tecnologia de produção e mercado. Vitória da Conquista: DFZ/UESB, 1986. p.1-6.

SILVA, A.R. da. Melhoramento genético para resistência à toxidez de alumínio e manganês no Brasil: antecedentes, necessidades e possibilidades. Ciência e Cultura, São Paulo,v.28, n.2, p.147-149, 1976.

SILVA, D.J.; LIMA, M.F. Influência de húmus de minhoca e de esterco de gado na concentração foliar de nutrientes e na produção de manga 'Tommy Atkins'. Revista Brasileira de Fruticultura, Jaboticabal, v.23, n.3, p.748-751, 2001.

SIMÃO, S. Tratado de fruticultura. Piracicaba: FEALQ, 1998. 760p.

SINGH, Z.; DHILLON, B.S. Effect of foliar application of boron on vegetative and panicle growth, sex expression, fruit retention and physico-chemical characters of fruits of mango (Mangifera indica L.) cv. Dusehri. Tropical Agriculture, Centeno, v.64, n.4, p.305-308, 1987.

SOARES, N.B. Comportamento de dezenove variedades de mangueira (Mangifera indica L.) na região de Bebedouro-SP. 1994. 140f. Tese (Doutorado em Produção Vegetal) - Faculdade de Ciências Agrárias e Veterinárias, Universidade Estadual Paulista, Jaboticabal, 1994.

VAN EEDEN, S.J. Calcium infiltration as a possible postharvest treatment to increase storage potencial of mango fruit. South African Mango Growers`Association Yearbook, Lonsdale, v.12, p.26-27, 1992.

YOUNG, T.W. Response of Kent mango to nitrogen fertilization. Proceedings of Florida State Horticultural Society, Ithaca, v.73, p.334-336, 1960.

YOUNG, T.W.; MINER, J.T. Relationship of nitrogen and calcium to "soft nose" disorder in mango fruits. Proceedings of the American Society for Horticultural Science, Ithaca, v.78, p.201-208, 1961.

ZAMBOLIM, L.; JUNQUEIRA, N.T.V. Manejo integrado de doenças da mangueira. In: ROZANE, D.E.; DAREZZO, R.J.; AGUIAR, R.L.; AGUILERA, G.H.A.; ZAMBOLIM, L. (Ed.). Manga: produção integrada, industrialização e comercialização. Viçosa: UFV, 2004. p.377-408. 